\title{
A study of computing doctorates in South Africa from 1978 to 2014
}

\author{
Ian D Sanders, Patricia M Alexander \\ School of Computing, University of South Africa
}

\begin{abstract}
This paper studies the output of South African universities in terms of computing-related doctorates in order to determine trends in numbers of doctorates awarded and to identify strong doctoral study research areas. Data collected from a variety of sources relating to Computing doctorates conferred since the late 1970s was used to compare the situation in Computing with that of all doctorates.

The number of Computing doctorates awarded has increased considerably over the period of study. Nearly three times as many doctorates were awarded in the period 2010-2014 as in 2000-2004. The universities producing the most Computing doctorates were either previously "traditional" universities or comprehensive universities formed by amalgamating a traditional research university with a technikon. Universities of technology have not yet produced many doctorates as they do not have a strong research tradition.

The analysis of topic keywords using ACM Computing classifications is preliminary but shows that professional issues are dominant in Information Systems, models are often built in Computer Science and several topics, including computing in education, are evident in both IS and CS.

The relevant data is in the public domain but access is difficult as record keeping was generally inconsistent and incomplete. In addition, electronic databases at universities are not easily searchable and access to HEMIS data is limited. The database built for this paper is more inclusive in terms of discipline-related data than others.
\end{abstract}

Keywords: tertiary education, information systems, computer science, information technology, doctorates awarded

Categories: Social and professional topics $\sim$ Computing education, Social and professional topics $\sim$ History of computing

\section{Email:}

Ian D Sanders sandeid@unisa.ac.za (CoRRESPONDING),

Patricia M Alexander alexapm@unisa.ac.za

\section{Article history:}

Received: 5 May 2015

Accepted: 6 Nov 2015

Available online: $10 \mathrm{Dec} 2015$

\section{INTRODUCTION}

Worldwide there has been an increase in the number of doctorates being awarded. Between 2001 and 2010, the number of new doctoral graduates increased in the EU-27 by $71 \%$; the US by $65 \%$ and Japan by 83\% (Deloitte Consulting, 2012). In just six years, between 1998 and 2004 Australia's delivery of doctorates grew by $46 \%$ (Nerad, 2009). However, the US Earned Doctorates statistics published by the National Science Foundation shows that the increase is not smooth: there are

Sanders, I.D., and Alexander, P.M. (2015). A study of computing doctorates in South Africa from 1978 to 2014 . South African Computer Journal 57, 58-89. http://dx.doi.org/10.18489/sacj.v0i57.294

Copyright (C) the author(s); published under a Creative Commons NonCommercial 4.0 License (CC BY-NC 4.0).

SACJ is a publication of the South African Institute of Computer Scientists and Information Technologists. ISSN 1015-7999 (print) ISSN 2313-7835 (online). 
periods when it falls, stagnates or rises sharply ${ }^{1}$. And this same source shows that in the US, whereas the number of doctorates awarded in science and engineering continue to rise, since the early 1970s the number of doctorates awarded in the other disciplines have remained unchanged at about 10,000. Rather more dramatically, the reported increase in annual number of doctorates awarded between 1991 and 2004 in China was 817\%, in Taiwan 379\%, and in South Korea 166\% (Nerad, 2009), (Nerad, 2011). Closer to home, six African universities in Cameroon, Nigeria, Benin, Senegal, Kenya and Rwanda had a combined 390\% growth in doctoral enrolments between 2005 and 2009 but this was off a low base and enrolments do not guarantee graduations (Kotecha, Steyn \& Vermeulen, 2012).

South Africa (SA) has relatively few doctorates compared with other countries, although figures vary: 26 per million of the population in 2007 (Academy of Science of South Africa, 2010; Wolhuter, 2011) or 28 per million of the population (Higher Education South Africa, 2014; RSA National Planning Commission, 2011). In 2007 SA was 33rd in a list of 34 countries in terms of number of doctorates per million population with the top country, Portugal, having 569, United States being further down with 201 (Academy of Science of South Africa, 2010). Korea and Brazil have 187 and 48 doctoral graduates per million (Higher Education South Africa, 2014). Table A1 gives total numbers of new doctorates for the period 2007 to 2011 for the Organisation for Economic Co-operation and Development (OECD) countries and other leading economies (OECD, 2013). Of the 36 countries with Science and Engineering (S\&E) figures, SA is tied 8th lowest in terms of the percentage of S\&E doctorates of all doctorates (10th lowest for all doctorates) and only Chile has fewer doctorates per million people in the population. Nevertheless there is a reported slow but steady growth of graduates (125\% increase from 2000 to 2012 or a 6.4\% average growth per annum between 1996 and 2012) (Cloete, Sheppard \& Bailey, 2015) and the SA figure is probably higher than other African countries. Directly comparable figures are not available but while doctoral enrolments in the SADC region are only $1 \%$ of total university enrolments, this decreases to $0.17 \%$ if SA is excluded (Kotecha et al., 2012).

The main reason put forward for policies that encourage more doctorates is that economic growth, particularly in the knowledge or smart economy, will be stimulated as a result (Nerad, 2011; Advisory Council for Science, Technology and Innovation, 2009). The SA government seems to accept this assumption (Academy of Science of South Africa, 2010; RSA National Planning Commission, 2011; de la Rey, 2014) but it is not entirely uncontested (Badat, 2014) and an increase in quantity should never be at the cost of quality (Nerad, 2011; Wolhuter, 2011; Herman, 2011; du Toit, 2012). There are various other versions of this claim, such as "increasingly, the public and private sectors in SA are stating that the doctorate is a requirement for certain positions" (de la Rey, 2014, p. 3), although there are counter claims that many employers do not consider a PhD to be necessary (Herman, 2011).

There are, however, other reasons for increasing the number of doctorates delivered each year: more than $50 \%$ of people with doctorates in SA, are employed at universities (Academy of Science of South Africa, 2010; Wolhuter, 2011) and this is also true of the countries surveyed in the OECD (OECD, 2013). It is important that a high percentage of academic staff should have doctorates

\footnotetext{
${ }^{1}$ http://www.nsf.gov/statistics/sed/2012/data_table.cfm
} 
(RSA National Planning Commission, 2011, pp. 318-9) but in SA for the period 2008-2010 only 35\% of academics had doctorates (Centre for Higher Education Transformation, 2013), up from 33\% in 2007 (Academy of Science of South Africa, 2010). The goal is to increase this to 75\% by 2030 (RSA National Planning Commission, 2011) and this means that many existing and newly appointed lecturers need to obtain doctorates. This is particularly urgent because by $202427 \%$ of current academics, including 50\% of professors and associate professors will retire (Higher Education South Africa, 2014).

In fact SA is already seen as being the African destination of choice for PhD students (the 11th biggest host country worldwide (Kotecha, 2012)). There has been a steady increase of international $\mathrm{PhD}$ students from the rest of Africa graduating from SA universities from $8 \%$ of all new doctorates in 2000 to $28 \%$ in 2012 (Figure 1) (Cloete et al., 2015).

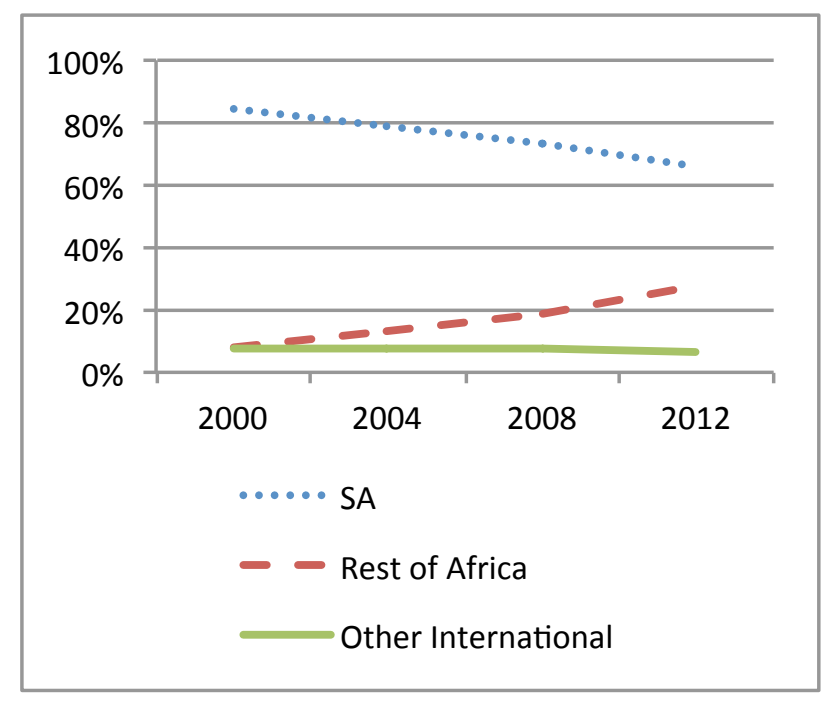

Figure 1: Percentage of doctorates awarded at South African public universities by nationality

In countries with a low birth rate and an aging population, attracting international doctoral candidates, many of whom remain in the country after graduating, is an important way of replacing highly qualified people who are intending to retire (Nerad, 2011). This also has benefits for the country from which the students come as, although they may spend some time working in their host country after graduating, the majority are likely to return home either immediately or later. Indeed one of the recommendations to government from the $\mathrm{PhD}$ study carried out by the Academy of Science of SA (ASSAf) is to assist SA citizens to study abroad with the expectation that they will return to SA after having qualified (Academy of Science of South Africa, 2010). The situation is, however, not totally clear. The (Academy of Science of South Africa, 2010) study claims that as many as $90 \%$ of students returned after studying outside of SA in the apartheid years, yet the same source says ('Finding 20') that a third of non-SA doctoral students studying in SA intend to stay in the country after graduating. In fact the number of foreign Science, Technology, Engineering 
and Mathematics (STEM) students intending to stay in SA may be much higher, as this same study says that skills shortages and job opportunities are a big factor in the decision whether to stay. The evident contradiction between these statements might be because although new graduates may stay in the host country for some years they may return home once their careers are established.

Another way of increasing the number of people with doctorates is to "import" non-SA academics with PhDs who can supervise doctorates, particularly experts in disciplines where there is a shortage of PhDs. The NPC suggests relaxing immigration requirements and granting work permits for extended periods to graduates from foreign countries in order to attract "science and mathematics teachers, technicians and researchers" (RSA National Planning Commission, 2011, p. 289).

The capabilities generated by doctoral study are not only advanced technological skills but include managerial and other professional skills, such as project management, personal time management, communication and writing skills (Nerad, 2009). Associated cognitive skills, such as improved critical thinking, innovation and creativity are useful to society as a whole (Academy of Science of South Africa, 2010) and personal life-skills, such as persistence and regard for high standards needed when polishing work, are also gained. Hence it is important to recognise that education to doctoral level has social implications and not just economic impact and that doctorates in the Arts, Humanities and Social Sciences, and not just the STEM disciplines, are important for the nation (Badat, 2014).

This paper recognises the importance of education to the doctoral level but presents information on the delivery of doctorates by South African universities in only one discipline, which we are electing to call Computing. The paper reports on a study of Computing doctorates awarded by SA universities from the late 1970s to 2014. Section 2 presents the objectives of the paper, Section 3 gives some background as regards postgraduate Computing programmes in South Africa, Section 4 expands on the context of the study with particular reference to the situation in South Africa and Section 5 is the literature review where we expand on the situation with particular reference to Computing PhDs. In Section 6 we discuss the issue of ranking in and diversification of South African universities. Section 7 discusses the methodology used in this paper while Section 8 comprises a discussion of the limitations of the paper. In particular, it discusses what the paper does not attempt to do. Section 9 presents the results of the paper and in Section 10 we discuss the relevance and implications of the results.

\section{OBJECTIVES OF THIS PAPER}

As mentioned earlier the focus of this paper is on the delivery of doctorates in one specific discipline, Computing, by South African universities. It explores the following research questions:

- What trends are evident in numbers of PhDs completed in Computing in SA?

- What $\mathrm{PhD}$ topic trends are evident in Computing in SA?

- What links are evident between trends and the contexts (or history or circumstances) of the set of universities exhibiting that trend? 
- What links are evident between trends and the IS and CS sub-disciplines?

The first two questions were addressed by collecting data regarding the awarding of Computing $\mathrm{PhDs}$ over the lifetime of the discipline in SA. Section 7 discusses how the data was collected and analysed and discusses some problems encountered in the collection process while Section 9 presents the results of the data collection exercise. The final questions are addressed in the Discussion (Section 10).

\section{SOUTH AFRICAN COMPUTING PROGRAMMES}

Prior to 2000, tertiary education in South Africa comprised universities and technikons which offered tertiary qualifications in Computing.

The restructuring of the South African university system between 2000 and 2005 resulted in new institution types. South Africa now has 23 public universities that comprise eleven traditional universities, six universities of technology and six comprehensive universities, which combine the functions of traditional universities and universities of technology. ... The eleven traditional universities offer academic and professional Bachelor degrees (usually 3 years in duration) and a small number of diplomas and certificates at the undergraduate level. Postgraduate degrees comprise of honours (a 1-year degree following the three-year Bachelor degree), masters and doctoral degrees as well as a limited number of postgraduate diplomas and certificates. Universities of technology offer a number of vocationally-oriented undergraduate diplomas as well as Bachelor of Technology degrees. Postgraduate study at universities of technology is limited to a relatively small number of masters and doctoral programmes. The comprehensive universities offer a combination of traditional university and university of technology programmes. (Ponelis et al., 2012)

Computing qualifications are offered at most of the universities.

The Accreditation Board for Engineering and Technology (ABET) identifies three sub-disciplines which fall within Computing, namely Computer Science (CS), Information Systems (IS) and Information Technology (IT) (Akbulut \& Looney, 2007) and ACM/IEEE curriculum recommendations exist for CS, computer engineering (CE), software engineering (SE) and IT (Topi et al., 2010) while ACM/AIS handles IS. This division and naming of sub-disciplines is not replicated uniformly across SA universities. Some, but not all, have separate CS and IS departments, which are often in different faculties. Universities of technology often have a Faculty of Information and Communication Technology within which they usually have more specialised departments such as: Software Engineering, Computer Systems Engineering, Informatics, Web and Multimedia Computing, Information Technology, Computer Science, and End User Computing. Comprehensive universities seem to have separate structures (departments or schools) within which degrees from traditional universities (including a $\mathrm{PhD}$ ) are presented independently from degrees and diplomas from the Technikon heritage (DTech, MTech etc.). For example, one such university has a School of Information and Communication Technology as well as a Department of Computing Sciences located in a different school. 


\section{CONTEXT}

There are many reports intended to influence government policy on higher education that are produced by international agencies and by national authorities in SA including the Centre for Higher Education Transformation (CHET) ${ }^{2}$ Southern African Regional Universities Association (SARUA) and ASSAf that track the progress and efficacy of education. These agencies generally report on accessibility, numbers of enrolments, time taken to complete and numbers graduating. The data are often analysed in terms of gender, population group, level of education and four main subject groups (STEM; Health; Social Sciences; Humanities). However there is little analysis done at a finer grained level in terms of subject studied: a single annual review of Computing higher education, covering North America, is the only study found (Zweben \& Bizot, 2013). This paper makes a start at understanding the SA situation as regards Computing doctorates awarded.

The case study by van Schalkwyk, Wilmers and Czerniewicz (2014) found that data is needed which allows a greater variety of analyses including comparisons and focussing on more specific issues or for a more specialised audience, such as for one particular discipline. Hence there is a request for more fine grained data, for example, by areas of specialisation (van Schalkwyk et al., 2014). The aforementioned project looks at open access data for higher education (such as the SA Higher Education MIS (HEMIS) data used almost exclusively in the reports referred to above ${ }^{3}$ ) and points out, firstly, that this data is not widely used by educational researchers, and secondly, does not seem to be easily accessible by them or to be structured in a way that makes it useful to them (van Schalkwyk et al., 2014). A contribution which was not initially intended for the current paper arises from our experience in collecting the data, which is supposed to be open access, and we suggest

\footnotetext{
${ }^{2}$ CHET was established in late 1996 as an NGO with international funding (USAID, Ford Foundation, UNESCO and Carnegie Corporation amongst others). Its mission is to mobilise trans-disciplinary skills for specific projects by tapping available expertise in the national and international higher education sector (Center for Higher Education Transformation, 2012). CHET provides a forum for interaction between the different structures, stakeholders, and constituencies in higher education. CHET collaborates actively with the Ministry of Education, the Committee of University Principals, the Committee of Technikon Principals, Committee of College Education Rectors South Africa, and the National Centre for Student Leadership. International collaborators include the American Council on Education, the Association for African Universities, the Commonwealth Higher Education Management Services, Centre for Higher Education Policy (Netherlands) and HEDDA, University of Oslo (Center for Higher Education Transformation, 2012).

CHET started with a high-profile South African Board but currently, only two Board members reside in South Africa, namely Brian O'Connell, Vice Chancellor of the University of Western Cape, and the Director of CHET, Nico Cloete (Center for Higher Education Transformation, 2012). CHET has always been located outside of a university, but its 'public' is the university and so are the researchers who investigate and report on issues. CHET operates on the boundary of the traditional academic-activist NGO models.

${ }^{3}$ The HEMIS data is collected by the Department of Higher Education and training from the 23 public (state affiliated) universities which are required to submit aggregate data on students, staff and building space annually. This data is publically available. HEMIS forms the basis for annual state funding allocations as well as system-level policy/steering (van Schalkwyk et al., 2014). CHET does some additional processing of this data such as data cleaning and verification and makes it available in a more easily accessible form across 20 performance indicators (http://chet.org.za/data/ sahe-open-data). However most recent figures are generally not available-in mid-2015 the 2012 data is the most recent found on the CHET site and the Statistics on Post-School Education and Training in South Africa: 2012 was published late in 2014 (RSA Department of Higher Education and Training, 2012).
} 
in our conclusions how the accuracy and accessibility of the data can be improved. The ASSAf says that more research is required beyond their own very strong study on doctoral education to develop a comprehensive understanding of the topic (Academy of Science of South Africa, 2010). CHET says, "Currently very few institutions produce data sets which would enable council members to engage meaningfully in discussions about the performance of the institution which they are entrusted to govern" (Bunting, Sheppard, Cloete \& Belding, 2010, p. 5).

Although many recommendations and policy statements suggest that STEM doctorates should be prioritised, the presentations to decision makers usually focus on the grand totals derived from the data for all disciplines together. This is partly as a result of the way that higher education data is currently collected and presented. Similarly, the recent White Paper for post-school education and training approved by cabinet in November 2013 and intended to shape post school education and training for the period up to 2030 included recommendations regarding differentiation of SA universities (RSA Department of Higher Education and Training, 2013). The authorities recommending differentiation explicitly state that the three basic categories of 'university', namely, traditional university', 'comprehensive university', and 'university of technology' should be retained but that the public university sector should in future be made up of a continuum of institutions ranging from specialised, research intensive universities to largely undergraduate institutions (Bunting et al., 2010; RSA Department of Higher Education and Training, 2013). The White Paper indicates that the entire university will be designated as a research institution based on statistics for the university as a whole. This is endorsed by CHET (Bunting et al., 2010) who emphasise that the institution and not educational programmes are the basic building blocks of the public university system and by the analyses done by CHET of performance indicators in South African higher education which use the institution as the unit of analysis. In addition, as will be seen from our results, the period of time over which an institution or some smaller part of it is assessed may be important. Hence this research contributes to the debate on differentiation of universities although those recommendations are not discussed in detail in the paper.

\section{LITERATURE REVIEW}

\subsection{Introduction}

In the introduction we note that not only is there a trend internationally of rapidly increasing graduation rates at the doctoral level, but that there are explicit policies to encourage this. Knowledge, skills and innovation are considered to be mutually reinforcing and science and technology knowledge and skills are linked particularly strongly to innovation.

\subsection{Reporting on computing doctorates}

There appears to be only one annual survey of degrees awarded in Computing and that is the Taulbee survey covering the US and Canada. The survey covering 2012 / 2013 (published in 2014 and the latest survey to date) reported that a record number of Computing $\mathrm{PhD}$ degrees had been awarded for 
the second consecutive year but predicts that this will level off over the next few years as enrolments have stabilized (Zweben \& Bizot, 2013).

In the majority of other reports, including those specific to SA, Computing is included with Engineering in Science and Technologies as is the case in the CHET open data on a high level knowledge production (Centre for Higher Education Transformation, 2013). However, Computing doctorates are counted as Natural and Agricultural Sciences in the ASSAf report and in that report no statistics are provided for this Computing subgroup. There were about $20 \%$ fewer natural science graduates than social sciences (Academy of Science of South Africa, 2010). Clearly this lack of uniformity in classification has made it difficult to compare reports.

ASSAf say that, "More studies are required on the careers of $\mathrm{PhD}$ graduates in specific fields and across the various sectors of employment." (Academy of Science of South Africa, 2010, p. 103) However, this is not easy to do although there is evidence of skill shortages in science and engineering in many countries (Bunting et al., 2010, p. 5). The specific issue of the supply and demand for Computing doctorates is not a well reported area and much of the published work is too old (The Economist, 2010; Moskal, 2002; Jones, 2003; Roberts, 2011; Freeman, Jarvenpaa \& Wheeler, 2000) to be relevant now. However it does indicate that the topic is important.

\subsection{Demand for computing PhDs}

Since $\mathrm{PhD}$ graduates play a particularly important role in research and innovation and science and technology are linked to innovation, Computing PhDs can be expected to be in demand. This is reflected in employment in the private sector in Ireland (Advisory Council for Science, Technology and Innovation, 2009), where the majority of researchers, with or without $\mathrm{PhD}$ degrees, are in ICT_-software and hardware (given as top of the list), pharmaceuticals and chemicals and medical devices. This is directly attributable to the fact that in Ireland $25 \%$ of business expenditure on Research and Development in 2007 was software and computer related. However, only a small percentage of ICT sector researchers (5\%) in Ireland were found to have PhD degrees.

In the 2009 ASSAf survey (Academy of Science of South Africa, 2010), the engineering, technology and materials sciences (ETM) (22\%) had the lowest percentage of PhD graduates employed by industry or the private sector followed by the natural and agricultural sciences graduates (within which Computing is counted) (48\%). The same survey found that $50 \%$ in this natural sciences group were employed by universities, which is lower than for any of the other groups of PhD graduates except ETM. As is the case with ETM doctorates, this group tended to move from being employed by the university before graduating to industry and private employment after graduating.

Natural sciences is the only group where there is no pile up of repeatedly enrolled $\mathrm{PhD}$ students who do not graduate and, compared to the other groups, the largest percentage of $\mathrm{PhDs}$ in this natural sciences group were of the opinion that the degree was crucial to their new employment (Academy of Science of South Africa, 2010). However, all of these ASSAf results apply to the combined natural and agricultural sciences group and no information is available regarding Computing PhDs specifically. 


\subsection{Employment of PhD graduates}

The OECD survey for 1990-2006 found that the unemployment rates of doctoral graduates across all disciplines do not exceed $2 \%$ or 3\% (Auriol, 2010). However the graduates are not necessarily fully employed, have permanent positions or are well paid; there is evidence that particularly in the academic world there is an over-supply of new PhDs other than in a few fast-developing countries (such as Brazil and China). Hence those who want to join a university as an academic member of staff need to accept a post-doc position for at least five years (The Economist, 2010).

The 2014 Taulbee survey indicates that 55.5\% of new Computing PhD graduates accepted positions in industry in North America, two thirds of which are research positions (Zweben \& Bizot, 2013). This same report says that approximately $18 \%$ of $\mathrm{PhD}$ graduates accepted relatively poorly paid post-doc positions in 2013/2014 either at universities or in industry. It is important to note that the PhD employment statistics for the Taulbee report are not entirely accurate as the employment status for about $20 \%$ of graduates is unknown. However the unemployment rate for the new Computing doctoral graduates is reported as consistently being below $1 \%$.

\section{SOUTH AFRICAN REPORTS}

\subsection{South African doctoral statistics}

Nine SA universities, the majority of which are well-established traditional universities, together produce more than $80 \%$ of the doctorates awarded (Academy of Science of South Africa, 2010). Table $1^{4}$ is useful for our purposes as it shows not only the universities that produced the highest numbers of doctorates overall in two separate years (2000 and 2007) but separately shows those producing the highest numbers of Natural Science doctorates amongst which Computing doctorates should be counted.

However this analysis does not refer to the size of the university or its access to resources and hence does not assess relative performance. Table 2 confirms that the majority (79\%) of doctorates are awarded by traditional universities but that over time in the Natural and Agricultural Sciences there is some fluctuation in the percentages for a university. Also, universities appear on the Natural and Agricultural Sciences list that are not in the overall list so different faculties in a university may differ in terms of productivity.

\footnotetext{
${ }^{4}$ Abbreviations of university names used in Tables 1 to 5 follow: CPUT Cape Peninsula University of Technology; CUT Central University of Technology; DUT Durban University of Technology; MUT Mangosuthu University of Technology; NMMU Nelson Mandela Metropolitan University; NWU North West University; RU Rhodes University; SU Stellenbosch University; TUT Tshwane University of Technology; UCT University of Cape Town; UFS University of the Free State; UJ University of Johannesburg; UKZN University of KwaZulu-Natal; UL University of Limpopo; Univen University of Venda; UP University of Pretoria; UZ University of Zululand; VUT Vaal University of Technology; WITS University of the Witwatersrand; WSU Walter Sisulu University.
} 
Table 1: Top 5 institutions in terms of their \% share of doctoral graduates, extracted from Academy of Science of South Africa (2010)

\begin{tabular}{|c|c|c|c|c|c|c|}
\hline \multicolumn{2}{|c|}{ Rank } & \multicolumn{5}{|c|}{ Field of study } \\
\hline \multirow{4}{*}{ All fields } & \multirow{2}{*}{2000} & UP & UCT & UJ & SU & WITS \\
\hline & & $14.0 \%$ & $12.4 \%$ & $10.9 \%$ & $10.2 \%$ & $10.0 \%$ \\
\hline & \multirow{2}{*}{2007} & $\overline{U P}$ & SU & UCT & WITS & NWU \\
\hline & & $13.3 \%$ & $12.0 \%$ & $11.1 \%$ & $10.5 \%$ & $9.7 \%$ \\
\hline \multirow{4}{*}{$\begin{array}{l}\text { Natural and } \\
\text { agricultural } \\
\text { sciences }\end{array}$} & \multirow{2}{*}{2000} & WITS & UP & UCT & UFS & UKZN \\
\hline & & $17.6 \%$ & $15.1 \%$ & $14.1 \%$ & $11.2 \%$ & $10.2 \%$ \\
\hline & \multirow{2}{*}{2007} & SU & WITS & UCT & UKZN & RU \& UP \\
\hline & & $14.1 \%$ & $13.5 \%$ & $13.0 \%$ & $11.6 \%$ & $9.1 \%$ \\
\hline
\end{tabular}

Table 2: Top 5 institutions in terms of their \% share of doctoral graduates, extracted from Academy of Science of South Africa (2010)

\begin{tabular}{|l|l|l|l|l|l|}
\hline & & Head counts & FTE enrol- & \multicolumn{3}{|c|}{ Annual averages for 2006-2008 } \\
\cline { 4 - 6 } & for 2008 & $\begin{array}{l}\text { Research } \\
\text { ments for }\end{array}$ & $\begin{array}{l}\text { Weighted } \\
\text { publications } \\
\text { research } \\
\text { output }\end{array}$ & $\begin{array}{l}\text { Doctoral } \\
\text { graduates }\end{array}$ \\
\hline Universities & 35 & 39 & 82 & 80 & 79 \\
\hline $\begin{array}{l}\text { Comprehensive } \\
\text { universities }\end{array}$ & 47 & 41 & 15 & 16 & 18 \\
\hline $\begin{array}{l}\text { Universities of } \\
\text { technology }\end{array}$ & 18 & 20 & 3 & 4 & 3 \\
\hline
\end{tabular}

\subsection{References to technology and computing in policy documents}

Although the Academy of Science of South Africa (2010, p. 117) is careful not to privilege one subject area over others, the National Development Plan (NDP) vision for 2030 emphasises the link between science and innovation and explicitly says most of the 5000 doctoral graduates envisaged for 2030 should be in the STEM fields (RSA National Planning Commission, 2011, p. 278). Computing is highlighted, with the recommendation that special consideration must be given to software engineering along with water, power, marine and space as part of a national system of innovation.

\subsection{Differentiation}

It is beyond the scope of this paper to explain how the university performance clustering was done by CHET (Bunting et al., 2010), and these clusters appear only to be preliminary. But the calculations used for the possible peer groupings proposed by CHET (Tables 3, 4 and 5) take into account the number of students enrolled at the university, its access to funding and numbers of research outputs 
and graduates. The different kinds of universities (traditional, comprehensive and university of technology) are assessed separately and grouped according to resources and compared in terms of how well they achieve a calculated output goal (based on 2006-2008 average output performance compared with target for the three output indicators). This exercise (peer grouping) is possibly only a proof of concept but is linked to the proposal that there should be differentiation and that possibly in future not all universities will be research universities or supervise doctorates (RSA National Planning Commission, 2011; Bunting, 2013; RSA Department of Higher Education and Training, 2013).

Table 3: Possible peer groupings for traditional universities (Bunting, Sheppard, Cloete \& Belding, 2010)

\begin{tabular}{|l|r|}
\hline Peer group & Weighted input \& output ratio (\%) \\
\hline \multicolumn{2}{|l|}{ Peer group 'W' } \\
\hline UCT & 100 \\
SU & 100 \\
RU & 93 \\
UP & 89 \\
\hline Peer group 'X' & 81 \\
\hline WITS & 70 \\
NWU & \\
\hline Peer group 'Y' & 56 \\
\hline UKZN & 52 \\
UFS & 52 \\
UWC & 52 \\
\hline UL & \\
\hline Peer group 'Z' & 37 \\
\hline UFH & \\
\hline
\end{tabular}

Table 4: Possible peer groupings for comprehensive universities (Bunting, Sheppard, Cloete \& Belding, 2010)

\begin{tabular}{|l|l|}
\hline Peer group & Weighted input \& output ratio (\%) \\
\hline Peer group 'C1' & 81 \\
\hline NMMU & \\
UJ & \\
\hline \multicolumn{2}{|l|}{ Peer group 'C2' } \\
\hline Univen & 67 \\
UZ & 56 \\
\hline Peer group 'C3' \\
\hline WSU & 33 \\
\hline
\end{tabular}


Table 5: Possible peer groupings for universities of technology (Bunting, Sheppard, Cloete \& Belding, 2010)

\begin{tabular}{|l|l|}
\hline Peer group & Weighted input \& output ratio (\%) \\
\hline \multicolumn{2}{|l|}{ Peer group 'T1' } \\
\hline CUT & 78 \\
CPUT & 70 \\
\hline Peer group 'T2' \\
\hline DUT & 59 \\
TUT & 59 \\
MUT & 52 \\
VUT & 41 \\
\hline
\end{tabular}

The White Paper (RSA Department of Higher Education and Training, 2013) strives to put differentiation in a positive light and to dispel some misconceptions, but there has been a great deal of anxiety about how many universities will be designated 'research universities', which of the many ways of measuring research and postgraduate excellence will be used, and what this will mean for the universities in terms of their being able to attract excellent students and staff, their government subsidies and their long term futures. The Higher Education SA (HESA) presentation to the Portfolio Committee on Higher Education and Training (Higher Education South Africa, 2014) touches on some of these issues. The issue as to whether a fine grained approach, such as a Computing specific analysis, should be taken into account in the differentiation debate will be raised in subsequent sections.

\subsection{Targets for South African PhD production}

The following are the recommendations included in the National Development Plan (RSA National Planning Commission, 2011) that are particularly relevant to this discussion:

a By $203075 \%$ of academics at SA universities should have doctorates.

b By 2030 the numbers of people choosing to work in the fields of science and technology should be three times as high as in 2011. Therefore the number of graduates in these fields needs to increase sharply.

c Not only must the number of doctorates per million citizens increase from 28 to 100 by 2030, the majority of these must be in science and technology. The total number of doctorates should increase from 1420 in 2010 to 5000 in 2030.

d Higher education should be diverse and institutions of higher education will be differentiated.

The NDP sets out recommendations that will assist in attaining these and other targets but as could be expected, barriers have been identified that could make these targets unrealistic or could result in lowering of standards (Herman, 2011; du Toit, 2012; Mohamedbhai, 2012). HESA says the goal of 
5000 doctorates is ambitious and stresses the need for adequate funding and a more detailed plan (Higher Education South Africa, 2014). The findings of the research which follow will be used in the Discussion to contribute empirical evidence as to whether the targets set are realistic for Computing.

\section{METHODOLOGY}

\subsection{Introduction}

This section is quite extensive as the lessons learned say a lot about the difficulties of collecting historical data in general, the use of open access databases where data is contributed by many separate organisations and possibly also contributes to a discussion on institutional repositories as part of their library information systems even though this was not a primary intention of the research. Furthermore, we believe that the credibility of the data is important (although disclaimers follow) as the results could be used in ways that affect universities. It is for this last reason that this paper will not name universities, supervisors or recipients of doctorates although a knowledgeable reader may be able to make "educated guesses". Concerns regarding the misinterpretation and misuse of open access data are not unique to this case, as noted by van Schalkwyk et al. (2014).

It is in the context of this broad data that we now delve more deeply into what actually happened over different universities over time.

\subsection{Research approach}

The research approach followed is illustrated in Figure 2. A case could be made that this research is positivist as it is based on factual data (the year, title, subdiscipline, degree conferred, and university) and some of the analysis is statistical (descriptive statistics only). Nevertheless, we believe it is presented in an anti-positivist way. There is no intention to be reductionist, to look at relationships as indicating cause and effect or even as being predictive, even though some conclusions will be presented. Rather we hope to present a reasonably rich picture in which the recent history of national higher education, that of individual universities and departments teaching Computing, and the individual interests of supervisors and candidates are all recognised as playing important roles in both the quantity and focus of the PhD theses being delivered over the past thirty years in SA.

Hence, the research approach used for this project is, in our opinion, best described as an descriptive case study (Yin, 2009) where the single case being considered is the production (delivery) of doctoral theses within the Computing disciplines in SA from the late 1970s to 2014. This is considered to be a unique single case with multiple levels of analysis (units of analysis at the national (SA) as well as individual university level). Although the first research question is answered entirely in terms of numbers, the second question required interpretation and no two analysts' classifications can be expected to agree exactly. We do not consider that mixed methods were used even though the primary data was collected in a variety of ways as all of these collected or confirmed a simple set of structured data. Data collection is described in more detail below. 


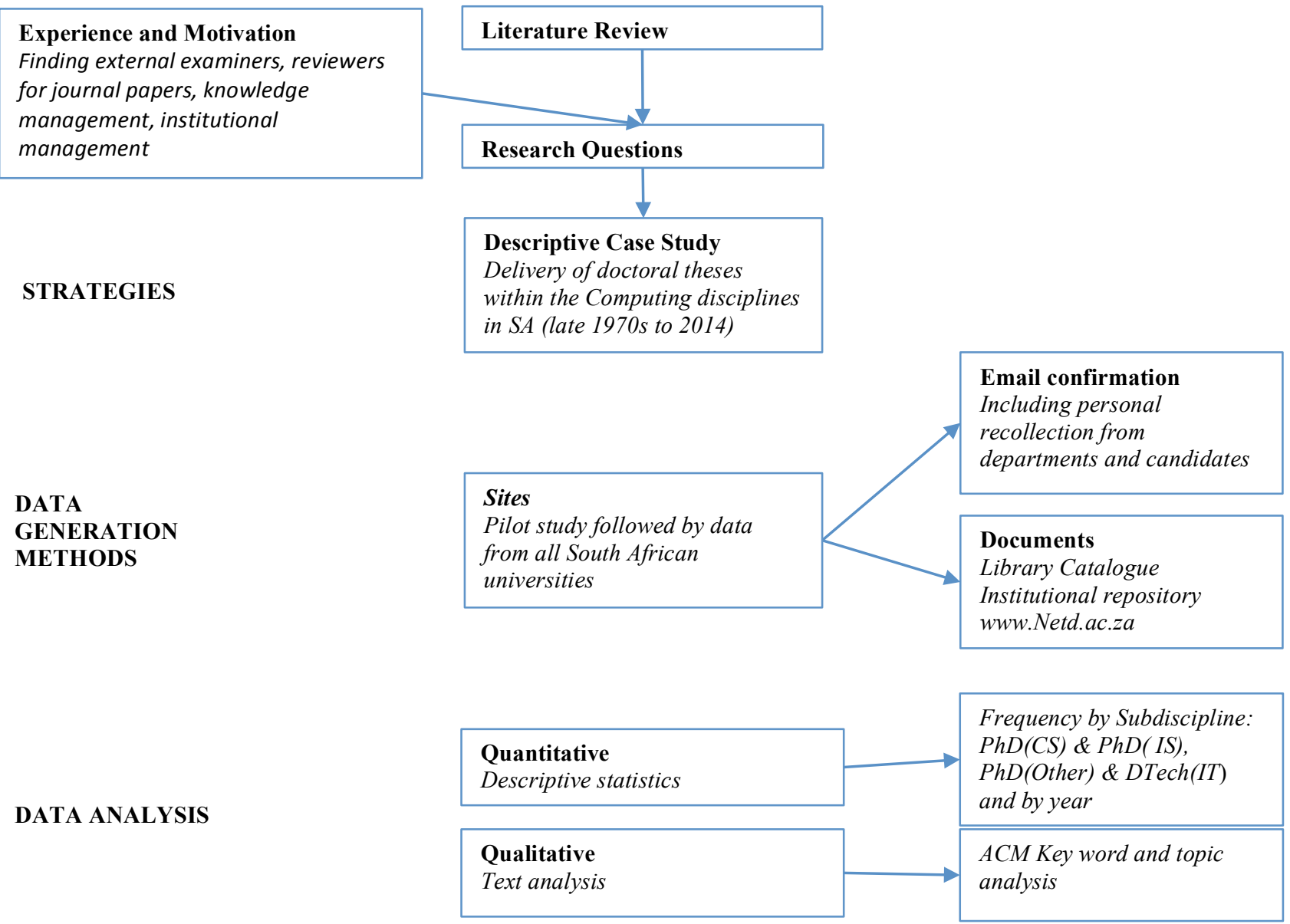

Figure 2: Research approach

\subsection{Data collection}

The first phase of data collection involved getting as complete a set of data as possible from one university where one of the authors had worked for many years including the time that the first candidate was awarded a $\mathrm{PhD}$ in the early 1980s. Collecting this data involved relying on personal memory (a common form of institutional knowledge) and was confirmed by contacting the very first recipients, accessing the library catalogue, the more recent electronic institutional repository, and the new, national repository of Masters and Doctoral theses and dissertations (www.netd.ac.za). This could be seen as being a pilot study and highlighted the fact that although hard copies of early theses are held in the library, locating them is difficult unless you have the author's name or the title of the work. It also revealed that the new databases (netd.ac.za and institutional repositories) are not particularly easy to search by means of a query as they do not necessarily contain fields indicating doctorate rather than Masters, discipline, or even the year the degree was awarded and even when such fields exist the data entry is inconsistent. Apparently the search capabilities of the netd database are limited because (to quote an email from one of the people closely associated with the database) 
"this is not a structured database so we cannot run a query. All the universities structure their data differently—some include supervisors and some don't and subject fields are notoriously ambiguous." Hence educational researchers face challenges in accessing data even from sources that provide open access.

The second phase involved collecting data from each of the other SA universities. Firstly, for every university a known contact at one of the Computing departments was approached via email and was asked who the appropriate person was to ask for assistance. This elicited various responses ranging from: an immediate complete list compiled by the first contact; referral to someone else who often then relayed the request to another person; a suggestion that the university repository and library catalogue be searched; assistance by setting up a query for the university's databases; and in a few cases no response at all. This was supplemented in all cases by personally accessing at least one additional open access source. This generally required looking at each entry within a faculty or school section and not being able to automatically separate the numerous Masters dissertations from doctoral theses made this time consuming.

The third phase involved sending the data collected for a particular university back to the person who was most involved in collecting the data at that university for validation. The responses varied from minor additions and changes to one where major errors were identified which were rectified and resubmitted for approval.

Despite the quite extensive efforts to collect reliable data we are aware that the data is not $100 \%$ complete. Information about very early doctorates, as mentioned above, relied on people remembering them (one person was sure his had not been the first at his university but he could not remember who the earlier candidate was and the suggested supervisor was not available). In addition, these early doctorates are often delivered by an engineering, mathematics or some other department which meant that finding them was largely a matter of luck! There is in fact quite considerable overlap between disciplines and hence the PhD (Other) category which we used to group theses from departments not primarily teaching Computing is rather contentious as it includes, as an example, theses on the use of technology in various aspects of education offered by Faculties of Education that are quite similar to theses delivered by particularly IS departments and mixed Computing departments. This particular category is acknowledged as having incomplete data. The decision as to what to include was largely a matter of personal judgement. Furthermore, information from 2013 and 2014 was not always already captured in the databases and overworked colleagues sometimes did not pick up this omission. Hence this end of the spectrum may also be slightly less reliable than earlier data.

\subsection{Data analysis}

In the data analysis phase of the research reported on in this paper we tried to discriminate between doctorates where the main focus is CS, IS or a DTech (IT) but acknowledge that there are grey areas and differences in nomenclature that made this goal difficult to achieve. Hence, we have grouped the doctorates into four categories, which for the sake of simplicity we name PhD (Computer Science), $\mathrm{PhD}$ (Information Systems), $\mathrm{PhD}$ (Other) and a single DTech, even though the actual degree awarded 
might be a DPhil, DCom, DSc, or DEng and the DTech does have some topics that are more CS or more IS in nature. Since many SA universities have a single department, the discipline designation given in the thesis title page for the degree was used in those cases in classifying, but early degrees were often not described other than as $\mathrm{PhD}$ and those were considered to be CS unless the title clearly indicates otherwise.

Topic analysis was handled separately by two senior academics, one who has worked in a specialised CS department for many years and the other who recently worked for more than ten years in a specialised IS department. It was considered more valuable for the CS specialist to analyse the CS data exclusively and similarly for the IS specialist to concentrate on the IS data as neither considered themselves sufficiently knowledgeable to handle all topics. Hence there is no attempt to calculate inter-coder reliability. This is acknowledged as a limitation of this analysis and is sufficiently serious to require the classification of this as exploratory research intended only to contribute preliminary findings and to initiate a further discussion on the topic. The codes were chosen primarily by understanding the title of the dissertation and then selecting a series of codes from the ACM Computing Classification System, 2012 Revision (Association for Computing Machinery, 2014). This classification system was chosen as it is well established, has recently been extensively revised and has credibility due to its status as the official ACM classification system. However it can also be criticised as IS is included as one of fifteen first level topics and hence appears to have been assigned a secondary status. Indeed, the comments made by Barki, Rivard and Talbot (1988, p. 302) in 1988 relating to a precursor to the ACM CSS, still seem to apply, even though the ACM classification was recently revised:

Unfortunately this Keyword list and classification scheme is not very useful for IS researchers because it was designed for computer science, which views IS as a subtopic. The IS descriptors used for the scheme are too few in number and scattered across several subtopics. As such, the scheme does not cover in sufficient detail the extent and variety of IS research.

Hence the ACM Computing Classification System (CSS) is not entirely suitable and sufficiently fine-grained for IS. This is a limitation in the IS $\mathrm{PhD}$ topic analysis. Specific IS keyword classification schemes do exist (for example, Barki et al. (1988)), but using separate systems for IS and CS can obscure overlapping interests.

As will be seen from the analysis of topics that follows, the topics of theses which are explicitly designated as "Information Systems" come from many other ACM categories as well. Analysis was done by using open source software to create Word Clouds. Word Clouds were decided on as an appropriate way to indicate dominant topics rather than more formal tables of frequencies or even graphs as this admittedly rather populist approach reflects the relatively informal allocation of codes based only on the thesis title. This analysis is intended to be preliminary as we acknowledge that it has not been verified.

This lack of any but the most limited information about the doctorate's topic is acknowledged as a further limitation. More than one code was often selected, and codes could be at any level within the classification system as we wanted to get a good match as far as keywords are concerned and to 
be able to justify the selection. An example from one thesis is given below. This thesis was assigned two separate codes, the first of which has three levels and the second with two levels:

13.1 Professional topics / Computing education / Information technology education

\subsection{Education / Collaborative learning}

The numbering was added by the authors but indicates that two different roots were involved. This level of detail would make any Word Cloud picture incorporating all the levels complex, so in a following step only the top level was retained, duplicates for the same thesis were eliminated, the list was sorted and separate Word Clouds were created for Computer Science and Information Systems.

\section{LIMITATIONS}

It is appropriate to make it clear what this study does not do. As seen in the Methodology section (Section 7), this study collected data of a different type and from new sources compared with the "big" national and international studies which generally use aggregated data originating from the HEMIS data and equivalent international databases. The data for the existing studies is sometimes supplemented with surveys, as in the case of Academy of Science of South Africa (2010). Hence this study is not directly comparable with "big" studies. The data collected covers as much of the time period as was possible in order to give a fully inclusive view rather than looking only at a recent period.

This study is not intended to provide all the evidence required to describe the strength of the research or standing of a particular university, school or department in terms of Computing but rather to illustrate the value of analysis at this level. Therefore universities are not referred to by name in this paper. (The authors, in fact, promised those individuals that assisted with the data collection that institutions and individuals would not be named.) This is its biggest difference from the national reports. This decision was made as the study is exploratory and was intended to be collegial rather than threatening; it is not based on a particular theory or expectations but was intended partly to develop a resource that captures some small aspects of institutional histories that were in danger of being lost. However on careful examination some interesting and hopefully useful phenomena emerged.

The study is limited to trends regarding numbers and topics; it does not discuss strategies for increasing throughput or the advisability and feasibility of increasing the number of doctoral candidates. There is no pedagogical discussion regarding types of doctorates such as Mode 1 or Mode 2 doctorates, methods of supervision or assessing quality.

Kotecha et al. (2012) ask: Do the number of doctoral degrees being produced and the disciplines in which they are produced become useful indicators of higher education's value as an agent of development? This is an important question which directly interrogates the wisdom and purpose of the four targets for SA PhD production given in Section 6.4. This paper has not attempted to evaluate the contributions made to society or the national economy by increasing the number of Computing doctorates. Nor has it been intended to add to the reputation of any one set of academics over another. 


\section{RESULTS}

\subsection{Trends in number of doctorates}

Data was obtained from 18 of the 23 universities; the five from whom no data was obtained / found happen to be five of the six with the lowest number of doctoral students enrolled in 2012 (RSA Department of Higher Education and Training, 2012). The sixth did reply but have their first doctoral candidate enrolled in 2014. The omission of these universities is unlikely to affect the results.

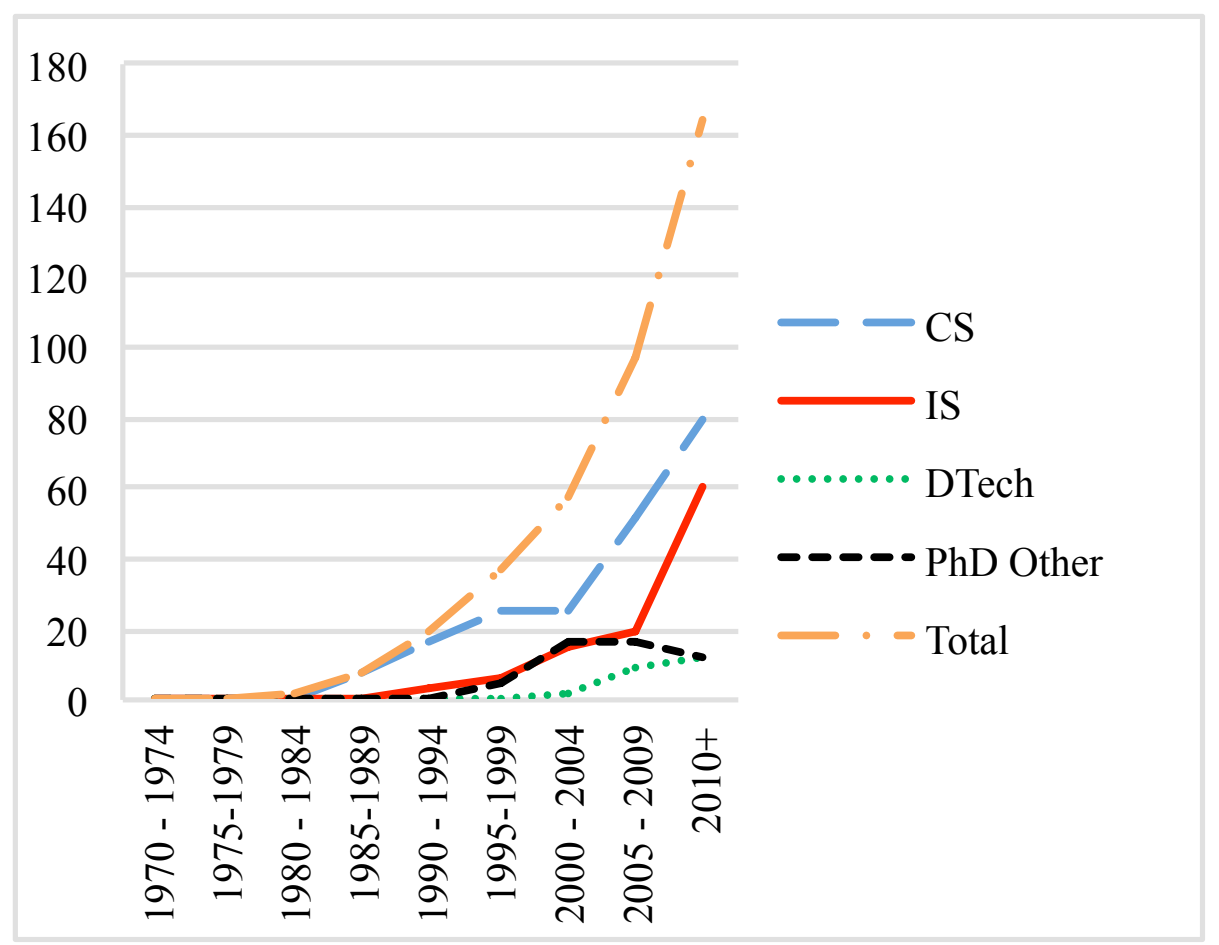

Figure 3: New computing doctorates (1974-2014)

Details of 391 doctorates were obtained. The distribution is shown in Figure 3. Thus there has been escalating growth over the period shown-in fact it grew by $173 \%$ from $2000-2004$ to 2010-2014 (59 to 161) compared with the $125 \%$ growth for all doctorates in SA over a similar period (2000 to 2012) reported by Cloete et al. (2015). Both CS and IS show particularly marked increases over the past ten years (CS after a period of low growth in the late 1990s picked up over the past 10 years and IS has grown very fast since 2009). This corresponds to some extent with the New Funding Formula's (NFF) introduction in 2004-2005, but outstrips other disciplines:

NFF financially supports the higher education institutions according to their research outputs (number of publications and number of postgraduate students produced). (Pouris, 2012, p. 1) 
This same author concludes that this particular strategy has also achieved the desired effect of increasing the quantity of high quality journal papers published by SA academics.

However, strangely, Computer Science is one of only three disciplines which is losing ground in terms of journal impact factor as this was better than the international norm $(1.1$, where the norm is 1) in 2000-2004 prior to the introduction of the NFF, but decreased to below that norm (0.9) in the subsequent five years (Pouris, 2012). Since we would expect that doctoral supervision requires publishable research this is an uncomfortable hint that the sharp increase in numbers of doctorates delivered over this period might be resulting in a drop in standards. The ASSAf are also aware of this danger (Recommendation 6):

However, if recent evidence on how funding incentives boosted journal publication is anything to go by, then there are clear warning signals ahead. Any mechanical increase in the production of $\mathrm{PhDs}$ in response to monetary incentives could jeopardise an already fragile quality spread across postgraduate qualifications, something brought to light in the work of the CHE. (Academy of Science of South Africa, 2010, p. 111)

In the next section of the paper we delve more deeply into what actually happened in different universities, in terms of $\mathrm{PhD}$ production, over time.

\subsection{The top six computing doctorate-producing universities in South Africa}

We examine three separate pairs of universities comprising the six which delivered the most Computing doctorates over the full period for which data was collected (given as since 1978 as prior to that doctorates were in the "other" category). These six universities contribute 242 of the 391 doctorates mentioned in Section 9.1 (Table 6). However, as can be seen in Table 6, Uni D regresses if we look only at the period since 2005. The two most productive universities, Uni A and Uni B, both are high achieving traditional universities in Peer Group W. They awarded almost twice as many doctorates (57 and 65, if $\mathrm{PhD}$ (other) are excluded) as the second tier. Uni C and Uni D both of which are high achieving comprehensive universities in Peer Group C1 awarded 31 each (again excluding PhD (Other)). Two small traditional universities, namely Uni E (Peer Group W) and Uni F (Peer Group Y), had between 19 and 23 Computing doctorates awarded. The statistics for the past ten years (2005-2009 and 2010-2014) from these three pairs of universities are studied in the analyses below but direct comparisons may be slightly unfair as the universities in each pair may have differently timed graduations affecting the 2014 data. Nevertheless the ebb and flow of doctorates in these finer grained analyses is evident.

It is important to note that although three of the Group W universities appear in the top 6 Computing list there is no correlation between the weighted input and output ratios awarded to the universities in Group W (Bunting et al., 2010) and their appearance on this Computing list. The two comprehensive universities on the other hand are indeed those scoring highest in the groupings for comprehensive universities (Bunting et al., 2010). Table 6 shows that the exclusion of "other" doctorates makes little difference to the totals after 2005.

Figure 4 shows outputs from Uni A and Uni B, one large and one medium sized (Bunting et al., 2010) well-resourced university, both in CHET's Peer Group W. Both universities' CS and IS 
Table 6: Possible peer groupings for universities of technology (Bunting, Sheppard, Cloete \& Belding, 2010)

\begin{tabular}{|l|r|r|r|r|r|r|r|}
\hline University & A & B & C & D & E & F & Total \\
\hline $\begin{array}{l}\text { Total since 1978 } \\
\text { Total since 1978 } \\
\text { excluding Other }\end{array}$ & 65 & 57 & 31 & 36 & 23 & 19 & 242 \\
\hline Total since 2005 & 51 & 46 & 24 & 15 & 15 & 18 & 169 \\
Total since 2005 & 48 & 46 & 24 & 12 & 15 & 15 & 160 \\
excluding Other & & & & & & & \\
\hline
\end{tabular}

departments are well established and from this data it is apparent that IS grew more noticeably than CS at both these universities and whereas in the 2005-2009 period there were fewer IS doctorates than CS, in the following 5 year period they delivered equal numbers. Uni A, which scored below Uni B in Group W overtook Uni B in both CS and IS in the 2010-2014 period. This illustrates that even sub-disciplines grow at different paces and the position of a university in the CHET groups may change quite rapidly when a finer grained analysis is done (of course this assumes that the input and output measures not included here remained constant).

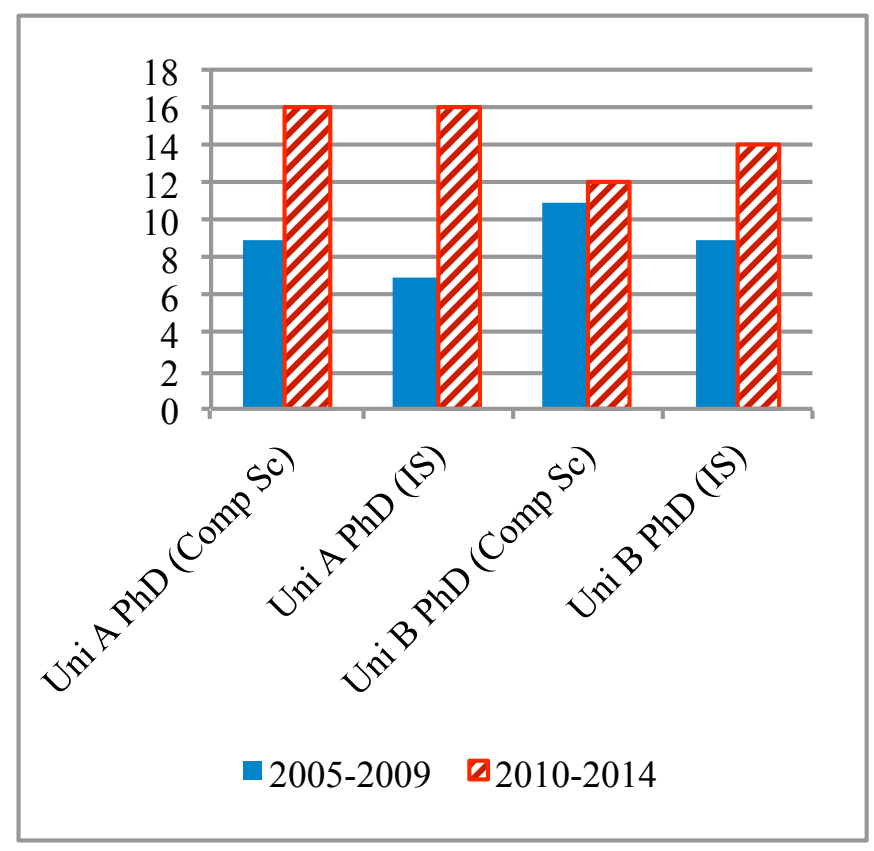

Figure 4: CS and IS doctorates for Uni A and Uni B (2005-2009; 2010-2014)

Figure 5 shows outputs from Uni C and Uni D (two of the six comprehensive universities) and here it is clear that whereas over the long term the total number of doctorates from Uni D was much higher than for Uni C, in the last four years Uni C is taking the lead. Hence this data repeats the 


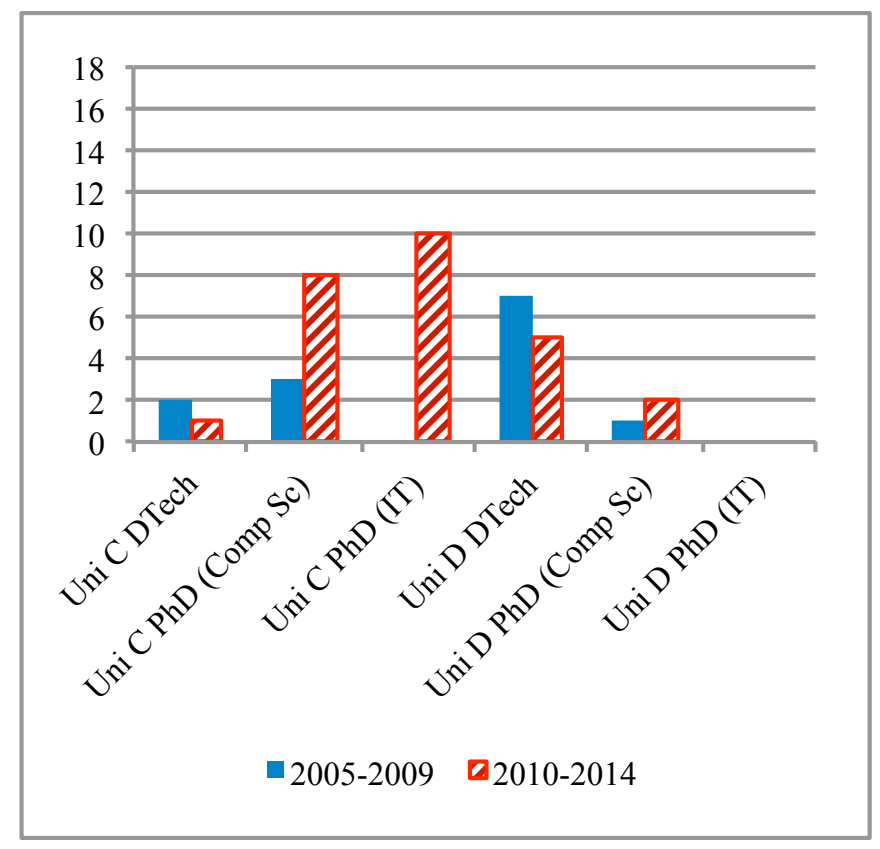

Figure 5: CS and IS doctorates for Uni C and Uni D (2005-2009; 2010-2014)

findings from Uni A and Uni B, namely that comparable (and possibly competing) universities do not necessarily maintain their positions even in the short term. Many things may cause relative strengthening in terms of supervision of doctorates; we are not jumping to any conclusions but overall student numbers, staff numbers, numbers of staff qualified to supervise doctorates, or loss of stalwart, that is, highly experienced supervisors, may be contributing factors. However, from this data the most obvious is contributions by sister departments. A single department, as is seen in Figure 5, may experience natural fluctuation but the existence of strong sister departments (CS, IT, DTech) can smooth out the impact of, for example, the loss of a stalwart supervisor. Uni C has such a distribution of doctorates between departments whereas Uni D depends almost entirely on CS. Nevertheless, Uni D is still in the top 4 in terms of total doctorates delivered.

Figure 6 shows statistics for Uni E and Uni F, which are two of the three small (an average of 10000 students enrolled in 2008 (Bunting, 2013)) but well-established universities in SA. This figure shows strong growth in CS but that IS is far less well established and appears even to be losing ground at these universities. Based on this data the challenge that smaller universities face in establishing and nurturing IS as a separate discipline at doctoral level is evident. Once again, the number of doctorates awarded in the most recent period at these two universities has reversed their previous positions and whereas Uni $\mathrm{E}$ is in Group W, Uni F in Group Y is outperforming it if we look only at the metric of PhDs awarded. 


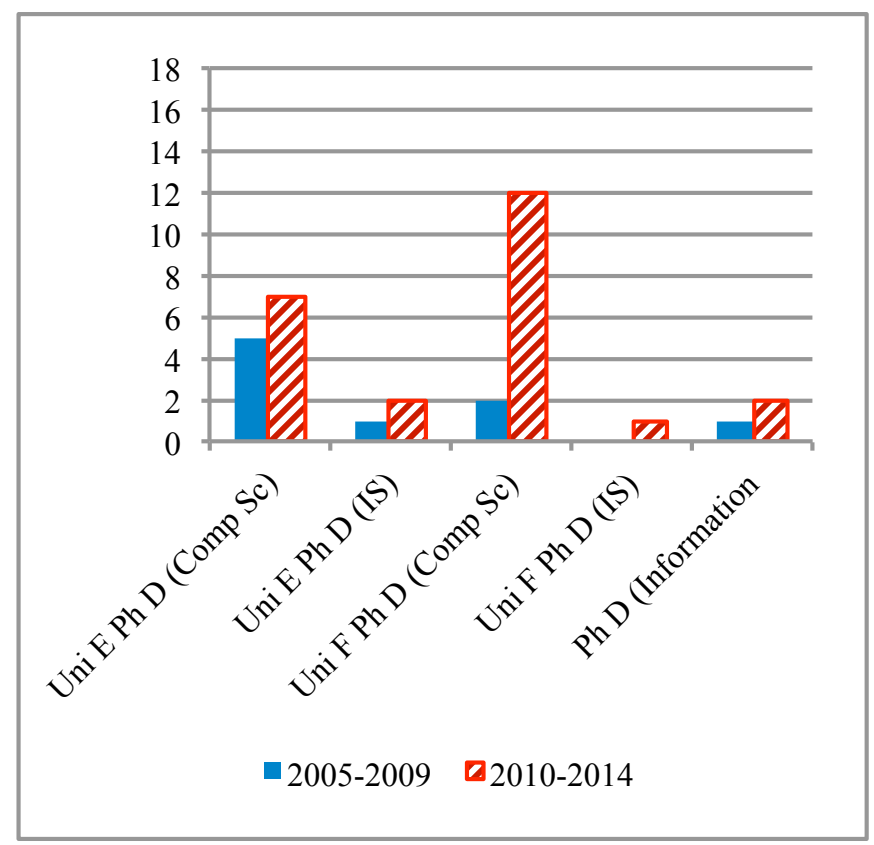

Figure 6: CS and IS doctorates for Uni E and Uni F (2005-2009; 2010-2014)

\subsection{Topics for IS doctorates}

Two hundred and four data items (key phrases) were used in the analysis for IS, each of the 104 IS doctorates ${ }^{5}$ have at least one key phrase assigned and not more than three such phrases. There is a relatively small number of ACM top-level focus areas which are dominant IS topics at SA universities (Figure 7). This is because the top-level topics cover a range of issues. The most extensively researched IS issues fall within one top-level item, indicated as "Professional" in Figure 7. Professional topics include a variety of sub-topics as listed in Table 7.

\footnotetext{
${ }^{5}$ Note that these are theses from all the universities over the entire period from 1978 to 2014 in contrast with Table 6 where only those from the top six universities were counted. PhD (IT), DCom (Inf) and some others were judged to be $\mathrm{PhD}$ (IS). PhD no specialization given from combined IS and CS departments were coded as PhD (CS). DTech was excluded as was "Other".
} 


\title{
Professional
}

LifeMedical

\author{
CollaborativeSocial
}

ISApps Education

EnterpriseComputing

HumanSocietalSecurityPrivacy

Adoption ICTD ISTheory

WWW SoftwareCreateManage

eCommerce

OtherDomains

Figure 7: IS thesis keywords

Table 7: Professional topics (Association for Computing Machinery, 2014)

\begin{tabular}{|c|}
\hline Computing industry \\
Industry statistics \\
Computer manufacturing \\
Sustainability \\
Management of computing and information systems \\
Project and people management \\
Implementation management \\
Software management \\
System management \\
Network operations \\
File systems management \\
Information system economics \\
History of computing \\
Computing education \\
Computational thinking \\
Accreditation \\
Model curricula \\
Computing education programs \\
Computing and business \\
Computing profession
\end{tabular}


These issues include managing all aspects of the development of an information system and the operation of the broader system as well as educating and training ICT professionals. A more detailed analysis of each of the top-levels would therefore prove more enlightening than the Word Cloud in Figure 7 but this is considered to be beyond the scope of this paper. In addition to the specialisations in terms of the disciplines there are also contexts or domains, and several of these are evident (examples are ICTD, LifeMedical which includes eHealth, and EnterpriseComputing). The most frequent context area is Education which refers to the use of ICT in education rather than education about ICT. Other domains cover: Digital libraries and archives; Publishing; Military; Cyberwarfare; Cartography; Agriculture; Computing in government; Voting / election technologies; E-government. Almost all empirical IS thesis have a domain of interest as well as a IS topic. The three non-ACM key phrases used are clearly important, namely ICTD (ICT for Development); Adoption (Technology adoption and use) and, to a lesser extent, Knowledge Management.

\section{ComputerGraphics}

\section{ModelingSimulation}

SystemsSecurity FornathethodsSecurityTheory

FormalLangsAutomataTheory

InformationRetrieval NetworkSecurity

TechnologyPolicy
OtherDomains Education NetworkAlgorithms

DependableFaultTolerant UbiquitousMobile MachineLearning

LifeMedical ICTD EnterpriseComputing

WWW Accessibility

AlgorithmDesignAnalysis

DataManagementSystems $\mathrm{HCI}$

Professional ISApps
HumanSocietalSecurityPrivacy

SoftwareCreateManage

DatabaseStorageSecurity

Figure 8: CS thesis keywords

\subsection{Topics for CS research}

Four hundred and thirteen data items (key phrases) were used in the analysis for $208 \mathrm{CS} \mathrm{PhD}$ theses, slightly more than twice as many key phrases and theses as for IS. The larger number of theses might explain the wider variety of key words in Figure 8 than in Figure 7. The high visibility of 
"Modeling-Simulation" caused the CS analyst to query the correctness of the analysis and it was found that this was due to the prevalence of the word "model" in CS thesis titles and hence this is a debatable classification under the ACM code "Model development and analysis".

It is interesting that IS applications (ISApps) features so predominantly in the Computer Science and the Information Systems thesis classifications. The full list of subcategories from the ACM classification is given in Table 8. It seems that many of the CS Computing PhDs focus on the more technical or science-oriented aspects of these subcategories.

Table 8: Information systems applications (Association for Computing Machinery, 2014)

\begin{tabular}{|l|}
\hline Enterprise information systems \\
Collaborative and social computing systems and tool \\
Spatial-temporal systems \\
Location based services \\
Geographic information systems \\
Sensor networks \\
Data streaming \\
Global positioning systems \\
Decision support systems \\
Data warehouses \\
Expert systems \\
Data analytics \\
Online analytical processing \\
Mobile information processing systems \\
Process control systems \\
Multimedia information systems \\
Multimedia databases \\
Multimedia streaming \\
Multimedia content creation \\
Massively multiplayer online games \\
Data cleaning \\
Collaborative filtering \\
Association rules \\
Clustering \\
Nearest-neighbor search \\
Data stream mining \\
Data mining libraries and archives \\
Computational advertising \\
Computing platforms \\
\hline
\end{tabular}


Human Computer Interaction (HCI) is shown to be a research topic in CS rather than in IS in SA. Machine Learning and related aspects of AI are popular thesis topics. Education (or Computer Science Education) topics are also prevalent. Security may not be highlighted to the extent that it should be as there are a number of security classifications at this level instead of a single, large "Security" label. Context (domain) key words appear less often than in IS.

\section{DISCUSSION}

In terms of the escalating number of doctorates for computing as a whole, particularly for the most recent two sets of five years (2005-2009; 2010-2014) it seems that the goals for 2030 regarding increases in doctorates awarded put forward by the NDP for the Computing discipline is realistic even if a significant number of senior professors retire in the next five years. This bodes well for improving the percentage of academic staff members in Computing with doctorates even if there is not as high a retention rate for doctoral candidates within university employ as there is in other disciplines. However, although this research has not made any attempt to look at quality, the associated indicators regarding publications emanating from the new degree-related research in Computing and its impact need to be monitored, as done for the whole spectrum of science research by Pouris (2012).

It is interesting that the six universities which have produced the largest number of computing doctorates over the full period being studied are universities that can clearly be differentiated either in terms of size (big traditional universities versus small traditional universities) or in terms of comprehensive versus traditional. The pairs of universities in this classification are adjacent (that is, appear next to one another) in the table of total numbers of doctorates delivered since 1978 (Table 6) and this also points to the influence of academic traditions. All were either previously "traditional research universities" or are comprehensive universities formed between 2000 and 2005 by amalgamating a traditional research university with a technikon. Universities of technology on the other hand have not inherited a research tradition and hence have not yet started producing many doctorates. It must be acknowledged that the universities of technology only relatively recently started supervising doctorates and only two are currently delivering doctorates. However, in contrast to overall reports which say that in 2007, the vast majority (at least $79 \%$ ) of all graduates were produced by Universities (as opposed to Universities of Technology and Comprehensive Universities) (Table 2) it is commendable that two comprehensive universities are making a big contribution in terms of Computing doctorates. Also it is remarkable that the very smallest of all the universities features among the "big six" in this research.

It is also interesting to note that one of the universities which had a particularly high score in the CHET peer groupings did not appear in the top 6 in the Computing list while one which was low on the CHET list was in the top 6 Computing universities. Regarding the university differentiation "threat", would the same universities feature as top research universities if different disciplines are analysed separately as in this piece of research? This research indicates that the performance of a university as a whole should not be seen as a predictor for faculties' or schools' performance and as a warning that if indeed differentiation is carried out for an entire institution, high-achieving units may disintegrate in terms of retaining researchers. There are quite rapid fluctuations over time within 
a university and between universities. The effect of natural changes in output relating to changes in human resources and particular leadership, recruitment, relocation and retirement of stalwarts indicates that the situation cannot be regarded as static or predictable and that remuneration, student funding, provision of infrastructure and national policy are only some of the features that influence academic productivity. CS and IS, or PhD (IT) and DTech may compete with one another and draw from a joint pool of candidates and shared research topics as discussed below.

The analysis of research topics shows that there is, historically but possibly also currently, quite considerable overlap between IS PhD topics and those in theses classified as CS PhDs in this paper. Keywords such as "Professional", "ISApps", "SoftwareCreateManage" , "LifeMedical" and "Education" feature prominently in both Word Cloud graphics. Although there are too few DTech degrees to analyse, it is likely that this is also evident there. This is partly because several universities have combined Computing departments and some of the data comes from the time before separate departments were created but the data shows that this overlap continues to occur when separate departments exist. The fact that other, non-computing departments also supervise doctorates on similar topics with or without co-supervisors from computing is also commonly accepted but data in this regard was not easily obtainable and hence the full extent of this is beyond the scope of this paper. This fluidity is considered to be good as inter-disciplinary research and trans-disciplinary research are increasingly welcomed and a sharing of the load between sister departments in times of stress is important. However, it does indicate that for research such as is done here the unit of analysis should be the faculty, school or other organisational structure dedicated to Computing as a whole and should not be too fine grained. Future analysis of topics may be more fruitful at a lower level of ACM classification but across the full spectrum of Computing rather than divided into IS and CS.

\section{REFLECTIONS AND CONCLUSIONS}

Referring back to the targets for SA PhD production given in Section 6.4, the first major conclusion of this paper is that the goal of significantly increasing the number of $\mathrm{PhD}$ graduates in science and technology, including those who are following careers as lecturers and researchers at universities, is realistic (goals a and c). This does not guarantee that more school leavers will decide to study Computing at university (goal b) but may contribute by increasing the number of role models. The issue of differentiated tertiary education (goal d) was also discussed and was found to be complex; no specific recommendations are made but the results of this research point out conflicts between our results within the Computing discipline, using a completely different data set, with those used by those proposing differentiation.

The usefulness of existing open access databases for quantitative analysis related to university registrations, graduations and student progress (provided by the universities to the HEMIS database) as well as access to dissertations and theses in other repositories has been raised. This depends on the quality of the data held in these databases in terms of accuracy, completeness and a uniform understanding of data items and the search tools. It is beyond the scope of this paper to explore this issue other than to confirm that currently this data is not easily accessed. The netd.co.za database 
goes some way to address the problem but could be improved by adding search options and in particular making it possible to discriminate between Masters dissertations and doctoral theses.

Furthermore, older and more importantly the most recent theses are not in the database or on the universities' own repositories. Updating these databases of course requires the cooperation of many people, as would be the case in trying to get the ACM keywords adopted for the Computing theses and dissertations, and may be almost impossible to institutionalize. The most reliable person to assign keywords is of course the author and it would be a mammoth task to get all the records of past work standardized. (Carefully controlled crowd-sourcing might be an option.) Future efforts could reach a compromise solution with keywords being assigned by knowledgeable academics in consultations with volunteers from the departments where the theses were supervised, but a discussion is needed as to whether this would be sufficiently useful. Other practical outcomes could include adding the names of the supervisors to the database set up for this research and making that database open access as this could be useful in selecting external examiners or requesting that a search according to supervisor be made possible on the other open access databases which hold information about theses. The database used in this paper is believed to be more complete in terms of inclusivity than others and hence could serve as a form of middleware which could be used to make data in other databases easier to access.

In summary, this paper shows that the number of Computing doctorates awarded in SA has increased over the lifetime of the discipline, apparently more rapidly than the rate for doctorates awarded overall in SA. Traditional universities are still the main providers of such degrees but comprehensive universities are making a strong contribution and universities of technology are likely to become more significant role players in the area in future. In terms of NDP goals it seems that Computing will be able to achieve the desired targets even with the expected loss of senior staff due to retirement. There are fluctuations within and between universities as regards production of doctorates. It seems that CS and IS, rather than being in competition for the same pool of students, complement and support each other and strong sister departments can smooth an institution's production over time.

\section{References}

Academy of Science of South Africa. (2010). The PhD study: An evidence-based study on how to meet the demands for high-level skills in an emerging economy. Accessed: 20 Nov 2015. Academy of Science of South Africa. Retrieved from http://www.pan.org.za/node/8639

Advisory Council for Science, Technology and Innovation. (2009, December). The role of PhDs in the smart economy. Retrieved from http://www.sciencecouncil.ie/media/asc091215_role_ of_phds.pdf

Akbulut, A. Y. \& Looney, C. A. (2007). Inspiring students to pursue computing degrees. Communications of the ACM, 50(10), 67-71. http://dx.doi.org/10.1145/1290958.1290964

Association for Computing Machinery. (2014). The 2012 ACM computing classification system. Retrieved from http://dl.acm.org/ccs_flat.cfm 
Auriol, L. (2010, March). Careers of doctoral holders: Employment and mobility patterns. OECD Science, Technology and Industry Working Papers. http://dx.doi.org/10.1787/5kmh8phxvvf5en

Badat, S. (2014, May). Transcription: Seminar on the doctorate in South Africa. Accessed 20 Nov 2015. Retrieved from http://www.chet.org.za/files/resources/02\%20Transcription\% 20PhD\%20seminar\%20May2014\%20Saleem\%20Badat.pdf

Barki, H., Rivard, S. \& Talbot, J. (1988). An information systems keyword classification scheme. MIS quarterly, 12(2), 299-322. http://dx.doi.org/10.2307/248855

Bunting, I. (2013, January). Differentiation in the South African higher education system. Accessed 20 Nov 2015. Retrieved from http://www.chet.org.za/files/resources/Ian\%20Bunting\% 20Differentiation\%20Slides\%2024\%20Jan\%202013.pdf

Bunting, I., Sheppard, C., Cloete, N. \& Belding, L. (2010). Performance indicators in South African higher education 2000-2008. African minds.

Center for Higher Education Transformation. (2012, August). Context and role in capacity-building and policy reform in South African higher education. Accessed 20 Nov 2015. Retrieved from http://www.chet.org.za/resources/chet-context-and-role-capacity\%C3\%A2\%C2\% 80\%C2\%90building-and-policy-reform-south-african-higher-education

Centre for Higher Education Transformation. (2013). Open data: A differentiated South Africa higher education system. Accessed 20 Nov 2015. Retrieved from http://www.chet.org.za/resources/ open-data-differentiated-south-africa-higher-education-system

Cloete, N., Sheppard, C. \& Bailey, T. (2015). Knowledge production and contradictory functions in African higher education. (Chap. South Africa as a PhD hub in Africa?, p. 75). Cape Town: African Minds. Retrieved from http://chet.org.za/books/knowledge-production-andcontradictory-functions-african-higher-education

de la Rey, C. (2014, May). Transcription: Seminar on the doctorate in South Africa. Accessed 20 Nov 2015. Retrieved from http://www.chet.org.za/files/resources/01\%20Transcription\% 20PhD_\%20seminar\%20May2014\%20Cheryl\%20de\%20la\%20Rey\%20Introduction. pdf

Deloitte Consulting. (2012). Director-General Research and Innovation: Researchers' report 2012. Accessed: 20 Nov 2015. Retrieved from http://ec.europa.eu/euraxess/pdf/research_ policies/121003_The_Researchers_Report_2012_FINAL_REPORT.pdf

du Toit, A. (2012, February). The PhD and the degree structure of South African higher education: A brief and rough guide. Retrieved from http://www.chet.org.za/files/PhD\%20Andre\% 20du\%20Toit.pdf

Freeman, L. A., Jarvenpaa, S. L. \& Wheeler, B. C. (2000). The supply and demand of information systems doctorates: Past, present, and future. MIS Quarterly, 24(3), 355-380. http://dx.doi. org/10.2307/3250966

Herman, C. (2011). Expanding doctoral education in South Africa: Pipeline or pipedream? Higher Education Research \& Development, 30(4), 505-517. http://dx.doi.org/10.1080/07294360. 2010.527928 
Higher Education South Africa. (2014, March). SA higher education in the 20th year of democracy: Context, achievements and key challenges. Accessed: 20 Nov 2015. Retrieved from http: //hesa2015. websiteinprogress.co.za/sa-higher-education-20th-year-democracycontext-achievements-and-key-challenges- 0

Jones, E. (2003). Beyond supply and demand: Assessing the Ph.D. job market. Occupational Outlook Quarterly, 46(4), 22-33.

Kotecha, P. (2012). Higher education in the Southern African region: Current trends, challenges, and recommendations. In Presentation to the Extraordinary Meeting of Ministries of Higher Education and Training, Johannesburg, South Africa (Vol. 5). Retrieved from http://www.sarua.org/?q= publications/sarua-presentation-ministerial-summit-0

Kotecha, P., Steyn, A. \& Vermeulen, P. (2012). The status quo of doctoral education in the SADC region. SARUA Leadership Dialogue Series, 4(1), 16-21.

Mohamedbhai, G. (2012, March). Are national goals for doctoral education realistic? University World News. Accessed 20 Nov 2015. Retrieved from http://www.universityworldnews.com/ article.php?story $=20120306150045171$

Moskal, B. (2002). Female computer science doctorates: What does the survey of earned doctorates reveal? ACM SIGCSE bulletin, 34(2), 105-111. http://dx.doi.org/10.1145/543812.543841

Nerad, M. (2009). The context for increasing the quantity and assuring the quality of doctoral education in South Africa: What we know about the increase in $\mathrm{PhD}$ production and reform of doctoral education worldwide. Unpublished paper presented at the Academy of Science of South Africa (ASSAf) panel on the PhD, Pretoria, SA.

Nerad, M. (2011). What we know about the dramatic increase in PhD degrees and the reform of doctoral education worldwide: Implications for South Africa. Perspectives in Education: The Changing Face of Doctoral Education in South Africa: Special issue 3, 29, 1-12.

OECD. (2013, October). OECD science, technology and industry scoreboard 2013: Innovation for growth. http://dx.doi.org/10.1787/sti_scoreboard-2013-en

Ponelis, S. R., Matthee, M. C., Buckley, S., Kroeze, J. H., Venter, I. M. \& Pretorius, P. D. (2012). Building capacity and developing human capital: An exploration of curriculum development in ICT programmes at South African universities. In Proceedings of SIG GlobDev Fifth Annual Workshop, Orlando, FL (Vol. 16).

Pouris, A. (2012). Science in South Africa: The dawn of a renaissance? South African Journal of Science, $108(7 \& 8), 1-6$.

Roberts, G. (2011, August). SET for success: The supply of people with science, technology, engineering and mathematics skills: The report of Sir Gareth Roberts' review. Accessed 20 Nov 2015. Retrieved from http://dera.ioe.ac.uk/4511/

RSA Department of Higher Education and Training. (2012). Statistics on post-school education and training in South Africa: 2012. Accessed 20 Nov 2015. Retrieved from http://www. dhet.gov.za/DHET\%20Statistics\%20Publication/Statistics\%20on\%20Post-School\% 20Education\%20and\%20Training\%20in\%20South\%20Africa\%202012.pdf

RSA Department of Higher Education and Training. (2013, November). White paper for post-school education and training: Building an effective, expanded and integrated post-school system. 
Accessed 20 Nov 2015. Retrieved from http://www.dhet.gov.za/SiteAssets/Latest\% 20News/White\%20paper\%20for\%20post-school\%20education\%20and\%20training. pdf

RSA National Planning Commission. (2011, November). National Development Plan: Vision for 2030. (Chap. Improving education, innovation and training, pp. 261-294). Accessed: 20 Nov 2015. Pretoria: RSA Government printers. Retrieved from http://www.gov.za/sites/www.gov.za/ files/devplan_2.pdf

The Economist. (2010, December). The disposable academic: Why doing a $\mathrm{PhD}$ is often a waste of time. Retrieved from http://www.economist.com/node/17723223

Topi, H., Valacich, J. S., Wright, R. T., Kaiser, K., Nunamaker Jr, J. F., Sipior, J. C. \& de Vreede, G.-J. (2010). IS 2010: Curriculum guidelines for undergraduate degree programs in information systems. Communications of the Association for Information Systems, 26(1), 18.

van Schalkwyk, F., Wilmers, M. \& Czerniewicz, L. (2014). Case study: Open data in the governance of South African higher education. Accessed 20 Nov 2015. Retrieved from http: //www.opendataresearch.org/sites/default/files/publications/Open\%20Data\%20in\% 20the \% 20Governance \% 20of \% 20South \% 20African \% 20Higher \% 20Education \% 20WEB.PDF

Wolhuter, C. (2011). Research on doctoral education in South Africa against the silhouette of its meteoric rise in international higher education research. Perspectives in Education: The Changing Face of Doctoral Education in South Africa: Special issue 3, 29, 126-138.

Yin, R. K. (2009). Case study research: design and methods (4th). Sage.

Zweben, S. \& Bizot, B. (2013, May). Taulbee survey. Computing Research News, 26(5), 10-55. 


\section{APPENDIX A}

Table A1: International statistics sorted by $\%$ of Science \& Engineering doctorates

\begin{tabular}{|c|c|c|c|c|}
\hline & All degrees 2007-2011 ${ }^{a}$ & S\&E degrees 2007-2011 ${ }^{a}$ & $\%$ of S\&E & Doctorates per million population $2007^{b}$ \\
\hline Mexico & 3702 & 1040 & $28 \%$ & 28 \\
\hline Hungary & 1217 & 373 & $31 \%$ & 105 \\
\hline Turkey & 4140 & 1382 & $33 \%$ & 48 \\
\hline Greece & 1855 & 625 & $34 \%$ & 218 \\
\hline Netherlands & 3425 & 1176 & $34 \%$ & 193 \\
\hline United States & 66931 & 23522 & $35 \%$ & 201 \\
\hline Korea & 10110 & 3561 & $35 \%$ & 187 \\
\hline South Africa & 1367 & 483 & $35 \%$ & 26 \\
\hline Slovak Republic & 1903 & 689 & $36 \%$ & 254 \\
\hline Portugal & 4104 & 1488 & $36 \%$ & 569 \\
\hline Brazil & 11123 & 4033 & $36 \%$ & 52 \\
\hline Norway & 1187 & 431 & $36 \%$ & 208 \\
\hline Germany & 25793 & 9722 & $38 \%$ & 297 \\
\hline Japan & 16272 & 6163 & $38 \%$ & 132 \\
\hline Australia (2007-10) & 5865 & 2337 & $40 \%$ & 264 \\
\hline Poland & 4626 & 1882 & $41 \%$ & 159 \\
\hline Finland & 1898 & 775 & $41 \%$ & 375 \\
\hline Switzerland & 3556 & 1460 & $41 \%$ & 454 \\
\hline Denmark & 1226 & 507 & $41 \%$ & 178 \\
\hline Austria & 2287 & 969 & $42 \%$ & 251 \\
\hline Spain & 7962 & 3378 & $42 \%$ & 159 \\
\hline New Zealand & 896 & 394 & $44 \%$ & 179 \\
\hline United Kingdom & 18127 & 8005 & $44 \%$ & 288 \\
\hline Italy $(2005,2006 \& 2011)$ & 10354 & 4585 & $44 \%$ & 173 \\
\hline Belgium & 1958 & 927 & $47 \%$ & 162 \\
\hline Slovenia & 455 & 216 & $47 \%$ & \\
\hline Sweden & 3564 & 1742 & $49 \%$ & 427 \\
\hline Czech Republic & 2347 & 1162 & $50 \%$ & 220 \\
\hline Israel & 1430 & 719 & $50 \%$ & 186 \\
\hline Estonia & 180 & 91 & $51 \%$ & 114 \\
\hline Iceland $(2007-10)$ & 25 & 13 & $52 \%$ & 32 \\
\hline Ireland & 1201 & 626 & $52 \%$ & 239 \\
\hline Canada (2007-10) & 5339 & 2900 & $54 \%$ & 140 \\
\hline China (2009-11) & 48568 & 27202 & $56 \%$ & \\
\hline France $(2007-10)$ & 12128 & 7200 & $59 \%$ & 172 \\
\hline Chile & 355 & 221 & $62 \%$ & 13 \\
\hline Indonesia & 3086 & N/A & & \\
\hline
\end{tabular}

${ }^{a}$ (Cloete, Sheppard \& Bailey, 2015) ${ }^{b}$ (Academy of Science of South Africa, 2010) 